\title{
Different responses of normal cells (red blood cells) and cancer cells (K562 and K562/Dox cells) to low-dose ${ }^{137}$ Cs gamma-rays
}

\author{
BENJAMAPORN SUPAWAT ${ }^{1,2}$, PANUMAS HOMNUAN ${ }^{1}$, NATTHAWAN KANTHAWONG ${ }^{1}$, \\ NIYADA SEMRASA ${ }^{1}$, SINGKOME TIMA $^{3}$, SUCHART KOTHAN ${ }^{1,2}$, \\ CHATCHANOK UDOMTANAKUNCHAI ${ }^{1}$ and MONTREE TUNGJAI ${ }^{1,2}$
}

\author{
${ }^{1}$ Department of Radiologic Technology; ${ }^{2}$ Center of Radiation Research and Medical Imaging, \\ Department of Radiologic Technology; ${ }^{3}$ Division of Clinical Microscopy, Department of Medical Technology, \\ Faculty of Associated Medical Sciences, Chiang Mai University, Chiang Mai 50200, Thailand
}

Received July 31, 2020; Accepted January 15, 2021

DOI: $10.3892 / \mathrm{mco} .2021 .2236$

\begin{abstract}
High-dose radiation is deleterious to cells or tissues. However, the health risks of exposure to low-dose radiation remain unclear. The present study aimed to investigate the biological responses of low-dose gamma-ray in vitro exposure to normal red blood cells (RBCs) and erythroleukemia (K562 and K562/Dox) cancer cells. Cells were given a low dose of $0.03,0.05$ and $0.1 \mathrm{mGy}$ of ${ }^{137} \mathrm{Cs}$ gamma-rays (at a dose rate of $0.001 \mathrm{~Gy} / \mathrm{min}$ ) under in vitro conditions. Cells exposed to $0 \mathrm{~Gy}$ served as controls. Hemolysis and reactive oxygen species (ROS) were measured in exposed RBCs following exposure to low-dose gamma-rays. In addition, complete blood count $(\mathrm{CBC})$ parameters were determined in irradiated whole blood. For irradiated K562 and K562/Dox cancer cells, ROS and mitochondrial activity were measured at $0,30,60$ and 120 post-irradiation times. The results showed no change in the percentage of ROS and hemolysis in irradiated RBCs. The data indicated no perturbation in the $\mathrm{CBC}$ parameters in irradiated whole blood. By contrast, statistically significant dose-dependent increases in the percentage of ROS and decreases in the mitochondrial activity in the K562 and K562/Dox cancer cells were observed from $0 \mathrm{~min}$ up to $120 \mathrm{~min}$ post-irradiation. These findings concluded that there were differences in biological responses in normal cells (RBCs) and cancer cells (K562 and K562/Dox) to low-dose gamma-rays when cells were irradiated under in vitro conditions.
\end{abstract}

\section{Introduction}

It is well known that a high dose of radiation is deleterious to cells or tissue (1-4). However, the health risks of exposure to

Correspondence to: Dr Montree Tungjai, Department of Radiologic Technology, Faculty of Associated Medical Sciences, Chiang Mai University, Building 2, 110 Intawaroros Road, Sripoom, Chiang Mai 50200, Thailand

E-mail: mtungjai@gmail.com

Key words: blood, cancer, low-dose radiation, gamma-ray, radiation low-dose radiation remain unclear. Several researchers have studied the biological response of normal cells or tissue to low doses of radiation using various biological endpoints such as neoplastic transformation, chromosome or DNA damage and immune function (5-17). In addition, several studies investigated the biological response of cancer cells or tissue to low doses of radiation using biological endpoints such as cell cycle and cell death (18-20). These studies showed differences in the biological response of normal and cancer cells or tissues to low dose radiation. Nonetheless, the limitation of the previous data on the response of normal and cancer cell or tissue to low-doses radiation is radiation doses in the range of centi Gray (cGy). Hence, the present study investigated the different responses of normal cells (blood cells) and cancer cells to low dose gamma-rays in the milli Gray (mGy) range.

These current studies focused on the four endpoints of biological responses that are recognized to be associated with oxidative stress induced by radiation. These biological responses are reactive oxygen species (ROS) levels, mitochondrial activity (which represents mitochondrial function), hemolysis (which represents plasma membrane integrity in red blood cells (RBCs)] and complete blood count (CBC). The focus was on ROS levels since it radiation (both low- and high-dose radiation) generates free radicals including ROS, resulting in oxidative damage in cells or tissues $(21,22)$. Oxidative stress is a disturbance in the balance between the yields of free radicals including ROS and antioxidant defenses (23). Typically, oxidative damage in cell or tissue induces mitochondria dysfunction or lipid peroxidation in plasma membranes (21,24-27). Mitochondrial dysfunction and plasma membrane damage is known to be involved in mitochondrial activity and red blood cell hemolysis, respectively. Moreover, the abnormal deformability of RBCs was observed in conditions linked to oxidative stress (28). In addition, radiation induced deleterious effects in blood cells in irradiated whole blood when compared with non-irradiated whole blood (29).

\section{Materials and methods}

Blood samples. Blood samples $(\mathrm{n}=10)$ were collected from remaining normal blood test group (males; age range, 40-50 years) 
at the Associated Medical Sciences Clinical Service Center, Faculty of Associated Medical Sciences, Chiang Mai University, Thailand.

Irradiation. Blood samples were given a dose of $0.03,0.05$ and $0.1 \mathrm{mGy}$ gamma-rays (at a dose rate of $0.001 \mathrm{~Gy} / \mathrm{min}$ ) using a ${ }^{137} \mathrm{Cs}$ radioactive standard source (located at the Department of Radiologic Technology, Faculty of Associated Medical Sciences, Chiang Mai University, Thailand). Samples exposed to 0 Gy served as controls. The equations were used to calculate radiation dose as following; i) $A t=A_{0} e^{-\lambda t}$; ii) $D=A_{t} \times \Gamma / d^{2}$.

When, $A_{0}$ and $A_{t}$ are the activity of radioactive present at $\mathrm{t}=0$ and time $=\mathrm{t} ; \lambda$, is decay constant; $\mathrm{D}$, is radiation dose; $\mathrm{d}$, is distance from radioactive; $\Gamma$, is specific gamma-ray constant.

Cancer cells and culture. Doxorubicin-sensitive erythroleukemia K562 cells (K562) and doxorubicin-resistant erythroleukemia K562 cells (K562/Dox, overexpressing P-glycoprotein) were provided by Dr Udomtanakunchai C. The cells were grown in RPMI-1640 medium supplemented with $10 \%$ fetal calf serum and $1 \%$ penicillin/streptomycin at $37^{\circ} \mathrm{C}, 95 \%$ humidity and $5 \% \mathrm{CO}_{2}$. The cells were seeded at a density of $1 \times 10^{5}$ cells $/ \mathrm{ml}$ then exponentially grown to $8-10 \times 10^{5}$ cells $/ \mathrm{ml}$ in 3 days. To obtain cells in the exponential growth phase for the experiments, cells were initiated at a density of $5 \times 10^{5}$ cells $/ \mathrm{ml}$. Cells were used for experiments $24 \mathrm{~h}$ later after reaching a density of $8-10 \times 10^{5}$ cells $/ \mathrm{ml}$.

Measurement of intracellular ROS levels. Cells $\left(5 \times 10^{5}\right.$ cells $\left./ \mathrm{ml}\right)$ were incubated with $10 \mu \mathrm{M}$ 2',7'-dichlorofluorescein (DCF) diacetate for $30 \mathrm{~min}$ in the dark. Subsequently, intracellular ROS levels were measured using fluorescence intensity at an emission wavelength of $523 \mathrm{~nm}$ (excitation wavelength, $502 \mathrm{~nm}$ ) using a fluorescence spectrometer (PerkinElmer, Inc.).

Mitochondrial activity. Living cells are able to reduce the nonfluorescent dye resazurin into the fluorescent dye resorufin via mitochondrial reductase. Hence, resazurin sodium salt (Sigma-Aldrich; Merck KGaA) was used to determine mitochondrial activity. Cells $\left(5 \times 10^{5}\right)$ were incubated with $100 \mu 1$ resazurin solution $(0.1 \mathrm{mg} / \mathrm{ml})$ in $1 \mathrm{ml} \mathrm{PBS}$ at $37^{\circ} \mathrm{C}$ and were humidified with $5 \% \mathrm{CO}_{2}$ for $2 \mathrm{~h}$. Subsequently, resazurin fluorescence intensity at a wavelength of $590 \mathrm{~nm}$ (excitation wavelength, $570 \mathrm{~nm}$ ) which is an indicator of mitochondrial activity in living cells was measured on a spectrofluorometer using a well-plate reader.

Hemolysis in normal RBCs. The hemolysis assay was performed based on previously published studies $(30,31)$. Briefly, $25 \mu 1$ of blood sample was incubated in $725 \mu \mathrm{l}$ PBS and in $725 \mu \mathrm{l}$ distilled $\mathrm{H}_{2} \mathrm{O}$ for $30 \mathrm{~min}$ at $37^{\circ} \mathrm{C}$. Next, blood samples were centrifuged at 7,000 rpm for $1 \mathrm{~min}$. The absorbance at wavelength $415 \mathrm{~nm}$ was recorded using a spectrophotometer (Agilent $8453 \mathrm{UV}$-vis spectrophotometer; Agilent Technologies, Inc.). The percentage of hemolysis was then calculated.

Determination of $C B C$ parameters in whole blood. CBC parameters were measured at the AMS Clinical Service Center, Faculty of Associated Medical Sciences, Chiang Mai University, Thailand. CBC parameters considered for the current included red blood cell count, hematocrit (HCT), mean corpuscular volume (MCV), red cell distribution width standard deviation (RDW-SD), white blood cell (WBC) count, neutrophil (NEUT) count, lymphocyte (LYMPH) count, monocyte (MONO) count, eosinophil (EO) count, basophil (BASO) count, platelets (PLT) count, platelet distribution width (PDW), pateletcrit (PCT) and mean platelet volume (MPV).

Statistical analysis. The data were expressed as the mean \pm SEM. An analysis of variance (ANOVA) method appropriate for a one-factor experiment (radiation dose) was used to assess the significance of radiation dose. Further, the post hoc test (Tukey test) was used to evaluate statistical differences in the mean values between each group. Student's t-test was used independently to evaluate statistical differences in the mean values between each test group and the corresponding control group. $\mathrm{P}<0.05$ was considered to indicate a statistically significant difference.

\section{Results}

Effect of low-doses gamma-rays on blood cells

Effect on ROS in normal RBCs. Fig. 1 shows the percentage of ROS in RBCs following in vitro exposure to various low doses of gamma-rays and in the corresponding non-irradiated control groups. The data showed no change in the percentage of ROS in irradiated RBCs relative to the corresponding non-irradiated RBCs (ANOVA test; P-value $=0.11$ ).

Effect on the percentage of hemolysis innormal RBCs. Fig. 2 shows the percentage of hemolysis in RBCs following in vitro exposure to various low doses of gamma-rays and in the corresponding non-irradiated control groups. The results showed that the percentage of hemolysis did not change in irradiated RBCs compared with corresponding non-irradiated RBCs (Student's t-test; P-value range, 0.61-0.87).

Effect on CBC parameters in whole blood. Table I shows the $\mathrm{CBC}$ parameters in whole blood following in vitro exposure to various low doses of gamma-rays. Similar to the percentage of ROS and hemolysis, this data indicated no alteration in the complete blood count in irradiated whole blood compared with the corresponding non-irradiated whole blood.

\section{Effect of low-doses gamma-rays on K562 and K562/Dox cancer cells}

Effect on ROS in cancer cells. Fig. 3 shows the percentage of ROS in K562 and K562/Dox cancer cells collected at 0, 30, 60 and $120 \mathrm{~min}$ after exposure to various low doses of gamma-rays. The data showed statistically significant dose-dependent increases in the percentage of ROS in the K562 and K562/Dox cancer cells from 0 min up to $120 \mathrm{~min}$ post-irradiation.

In K562 cancer cells, the increases were 1.04-, 1.08- and 1.10 -fold higher compared with the control at 0 min post-irradiation; 1.06-, 1.11- and 1.20-fold higher compared with the control at 30 min post-irradiation and 1.10-, 1.17- and 1.28-fold higher compared with the control at 60 min post-irradiation. Likewise, the increase in ROS levels in exposed cells at 120 min post-irradiation were 1.17-, 1.22- and 1.29-fold higher compared with the control.

In K562/Dox cancer cells, at 0 min post-irradiation, the increases were 1.02-, 1.05- and 1.09-fold higher compared 
Table I. Complete blood count parameters in whole blood following in vitro exposure to various low doses of gamma-rays.

\begin{tabular}{|c|c|c|c|c|c|c|c|}
\hline \multirow[b]{3}{*}{ Parameters } & \multicolumn{7}{|c|}{ Radiation dose } \\
\hline & \multirow{2}{*}{$\frac{0 \mathrm{mGy}}{\text { Mean } \pm \mathrm{SE}}$} & \multicolumn{2}{|c|}{$0.03 \mathrm{mGy}$} & \multicolumn{2}{|c|}{$0.05 \mathrm{mGy}$} & \multicolumn{2}{|c|}{$0.1 \mathrm{mGy}$} \\
\hline & & Mean $\pm \mathrm{SE}$ & P-value & Mean $\pm \mathrm{SE}$ & P-value & Mean $\pm \mathrm{SE}$ & P-value \\
\hline $\operatorname{RBC}\left(10^{6} / \mu 1\right)$ & $2.86 \pm 0.36$ & $2.40 \pm 0.05$ & 0.29 & $2.30 \pm 0.14$ & 0.23 & $2.20 \pm 0.14$ & 0.17 \\
\hline $\operatorname{HCT}(\%)$ & $24.58 \pm 3.22$ & $20.90 \pm 0.55$ & 0.34 & $20.02 \pm 1.16$ & 0.26 & $19.14 \pm 1.28$ & 0.19 \\
\hline $\operatorname{MCV}(f l)$ & $85.93 \pm 2.88$ & $87.20 \pm 2.53$ & 0.75 & $87.20 \pm 2.58$ & 0.75 & $86.98 \pm 2.51$ & 0.79 \\
\hline RDW-SD (fl) & $40.05 \pm 1.32$ & $41.76 \pm 2.08$ & 0.51 & $41.68 \pm 2.02$ & 0.52 & $41.58 \pm 1.87$ & 0.53 \\
\hline $\operatorname{PLT}\left(10^{3} / \mu 1\right)$ & $77.75 \pm 11.24$ & $105.00 \pm 21.10$ & 0.30 & $106.40 \pm 20.60$ & 0.27 & $107.00 \pm 21.34$ & 0.27 \\
\hline PDW (fl) & $11.88 \pm 0.83$ & $11.52 \pm 0.99$ & 0.79 & $11.34 \pm 0.71$ & 0.64 & $11.08 \pm 0.81$ & 0.51 \\
\hline MPV (fl) & $10.65 \pm 0.29$ & $10.04 \pm 0.44$ & 0.29 & $10.10 \pm 0.39$ & 0.30 & $10.08 \pm 0.36$ & 0.26 \\
\hline $\operatorname{PCT}(\%)$ & $0.08 \pm 0.01$ & $0.10 \pm 0.02$ & 0.39 & $0.11 \pm 0.02$ & 0.32 & $0.10 \pm 0.02$ & 0.39 \\
\hline WBC $\left(10^{3} / \mu 1\right)$ & $4.03 \pm 0.32$ & $4.12 \pm 0.24$ & 0.83 & $4.15 \pm 0.37$ & 0.82 & $4.05 \pm 0.37$ & 0.98 \\
\hline NEUT (\%) & $62.63 \pm 3.95$ & $59.42 \pm 3.63$ & 0.57 & $59.06 \pm 3.79$ & 0.54 & $58.14 \pm 3.45$ & 0.42 \\
\hline LYMPH (\%) & $28.75 \pm 3.82$ & $30.32 \pm 3.36$ & 0.77 & $30.86 \pm 3.38$ & 0.69 & $31.60 \pm 3.31$ & 0.59 \\
\hline MONO (\%) & $5.73 \pm 0.60$ & $6.84 \pm 0.16$ & 0.16 & $6.48 \pm 0.25$ & 0.31 & $6.86 \pm 0.24$ & 0.16 \\
\hline $\mathrm{EO}(\%)$ & $2.73 \pm 0.36$ & $3.28 \pm 0.97$ & 0.61 & $3.46 \pm 1.10$ & 0.55 & $3.36 \pm 1.02$ & 0.58 \\
\hline BASO (\%) & $0.18 \pm 0.06$ & $0.14 \pm 0.06$ & 0.70 & $0.14 \pm 0.06$ & 0.70 & $0.04 \pm 0.04$ & 0.13 \\
\hline
\end{tabular}

RBC, red blood cell; HCT, hematocrit; MCV, mean corpuscular volume; RDW-SD, red cell distribution width standard deviation; PLT, platelets; PDW, platelet distribution width; MPV, mean platelet volume; PCT, pateletcrit; WBC, white blood cell; NEUT, neutrophil; LYMPH, lymphocyte; MONO, monocyte; EO, eosinophil; BASO, basophil; SE, standard error.

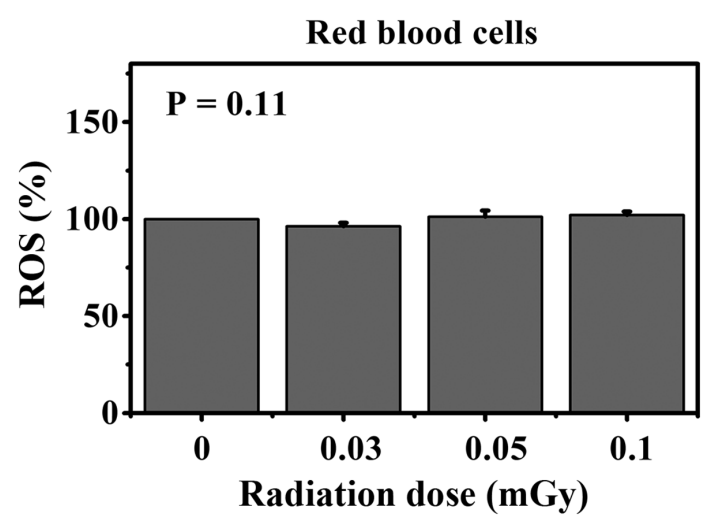

Figure 1. Reactive oxygen species percentage in red blood cells following in vitro exposure to various low doses of gamma-rays and in the corresponding non-irradiated control groups. ROS, reactive oxygen species.

with the control; at 30 min post-irradiation, the increases were 1.03-, 1.05- and 1.11-fold higher compared with the control and at $60 \mathrm{~min}$ post-irradiation, the increases were 1.04-, 1.05- and 1.11-fold higher compared with the control. Likewise, the increase in ROS levels in exposed cells at 120 min post-irradiation were 1.03-, 1.06- and 1.11-fold higher compared with the control.

Effect on mitochondrial activity in cancer cells. Fig. 4 shows the mitochondrial activity in K562 and K562/Dox cancer cells, collected at $0,30,60$, and 120 min following exposure to various low doses of gamma-rays. The results showed statistically significant dose-dependent decreases in the mitochondrial activity of K562 and K562/Dox cancer cells from $0 \mathrm{~min}$ up to $120 \mathrm{~min}$ post-irradiation.

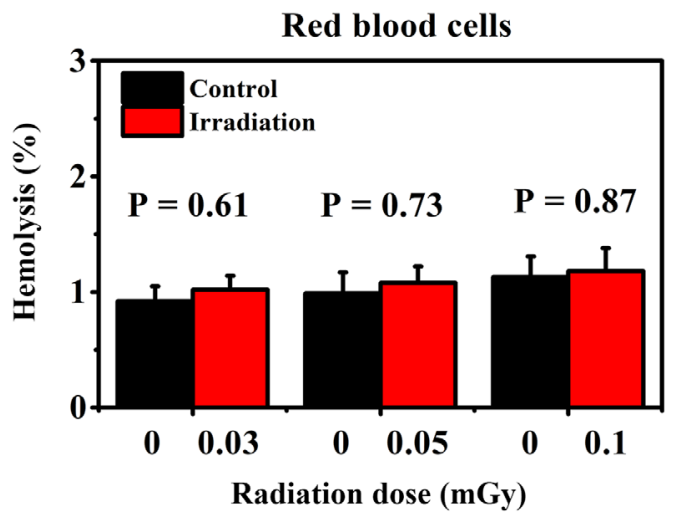

Figure 2. Hemolysis percentage in red blood cells following in vitro exposure to various low doses of gamma-rays and in the corresponding non-irradiated control groups.

In K562 cancer cells, at 0 min post-irradiation, the decreases were $0.98-, 0.89$ - and 0.83 -fold lower compared with the control; at 30 min post-irradiation, the decreases were $0.96-, 0.87$ - and 0.81 -fold lower compared with the control, and at $60 \mathrm{~min}$ post-irradiation, the decreases were 0.94-, 0.84- and 0.79-fold lower compared with the control. Likewise, the decreases in the mitochondrial activity of exposed cells at 120 min post-irradiation were 0.89 -, 0.83 - and 0.75-fold lower compared with the control.

In K562/Dox cancer cells, the fold decrease in the mitochondrial activity were dose-dependent at all four timepoints relative to the corresponding controls: $0.99,0.92$ and 0.83 at 0 min post-irradiation; $0.98,0.88$ and 0.82 at 30 min post-irradiation; $0.96,0.85$ and 0.79 at 60 min post-irradiation and 0.94 , 0.83 and 0.76 at 120 min post-irradiation. 

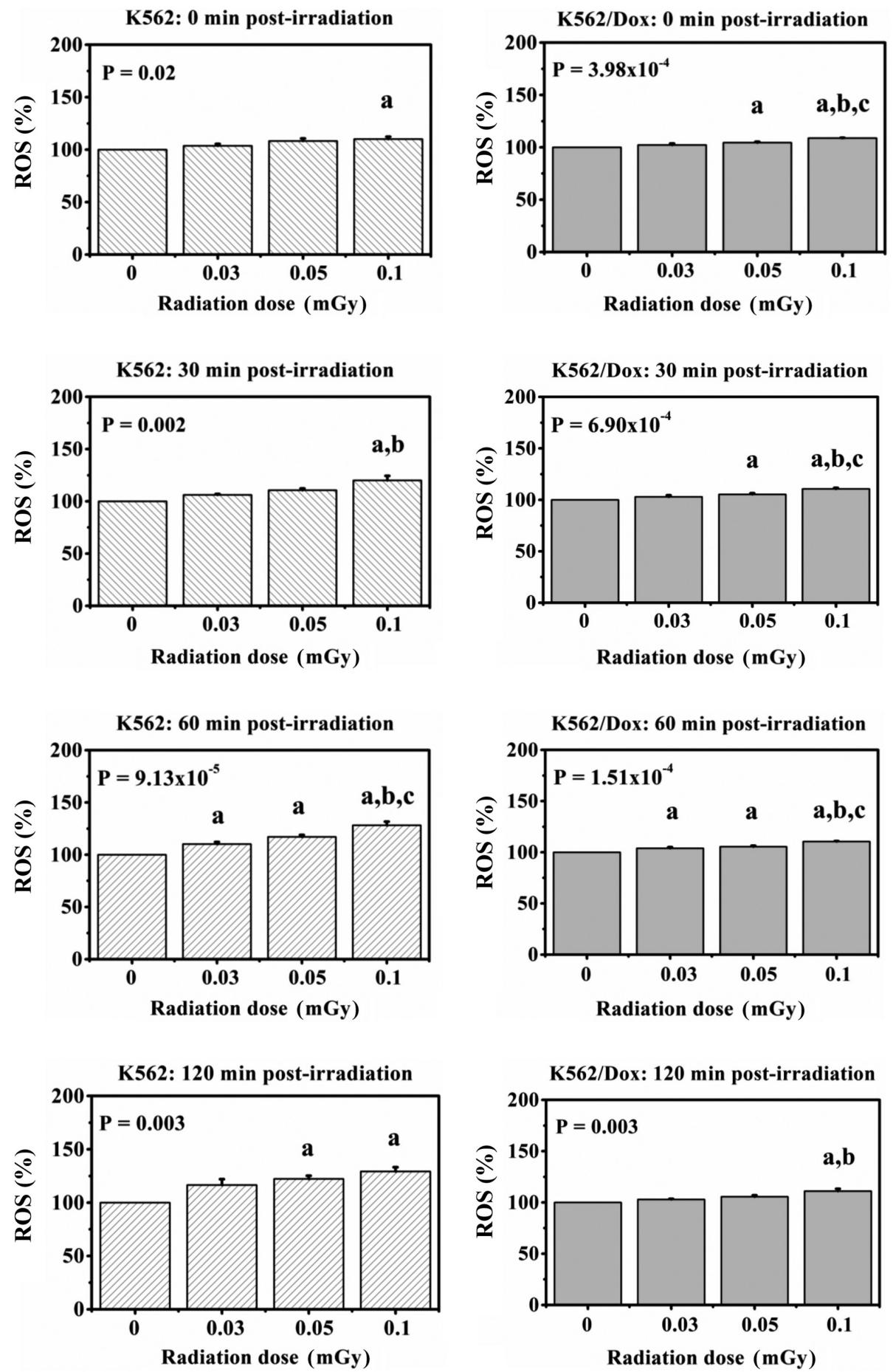

Figure 3. ROS percentage in K562 and K562/Dox cancer cells collected at 0, 30, 60 and 120 min after exposure to various low doses of gamma-rays. ${ }^{\mathrm{a} P}<0.05$ vs. $0 \mathrm{mGy} ;{ }^{b} \mathrm{P}<0.05$ vs. $0.03 \mathrm{mGy}$; and ${ }^{\mathrm{c}} \mathrm{P}<0.05$ vs. $0.05 \mathrm{mGy}$. ROS, reactive oxygen species.

\section{Discussion}

The dose ranges of the gamma-rays damage to normal RBCs in vitro were reported in IAEA-TECDOC-934 document. This document reported that examining the nature of the membrane injury in gamma irradiated RBCs in the dose range 2 to $200 \mathrm{~Gy}$, It was concluded that the sulphydryl group was the major target in radiation-induced alteration of sodium and potassium ion permeability. In addition, an in vitro study on the effect of $\mathrm{X}$-rays on movement of sodium in human RBCs, showed a loss of sodium/potassium ion balance in $\mathrm{RBCs}$, following radiation doses in the range of 8.9 to $89 \mathrm{~Gy}$. This phenomenon was due in part to discontinuation of membrane integrity (32). However, those radiation dose ranges are rather highly and most that dose find in radiation accident or radiotherapy. Whereas radiation dose in low-dose range that find in diagnostic radiology or nuclear medicine examination is still challenges. Our previous studies investigated biological responses to radiation after blood tissue was exposed to low dose X-rays in an in vitro system. The results showed that hemolysis and osmotic fragility in irradiated human RBCs did not significantly differ from non-irradiated RBCs. The results also showed that low-dose 

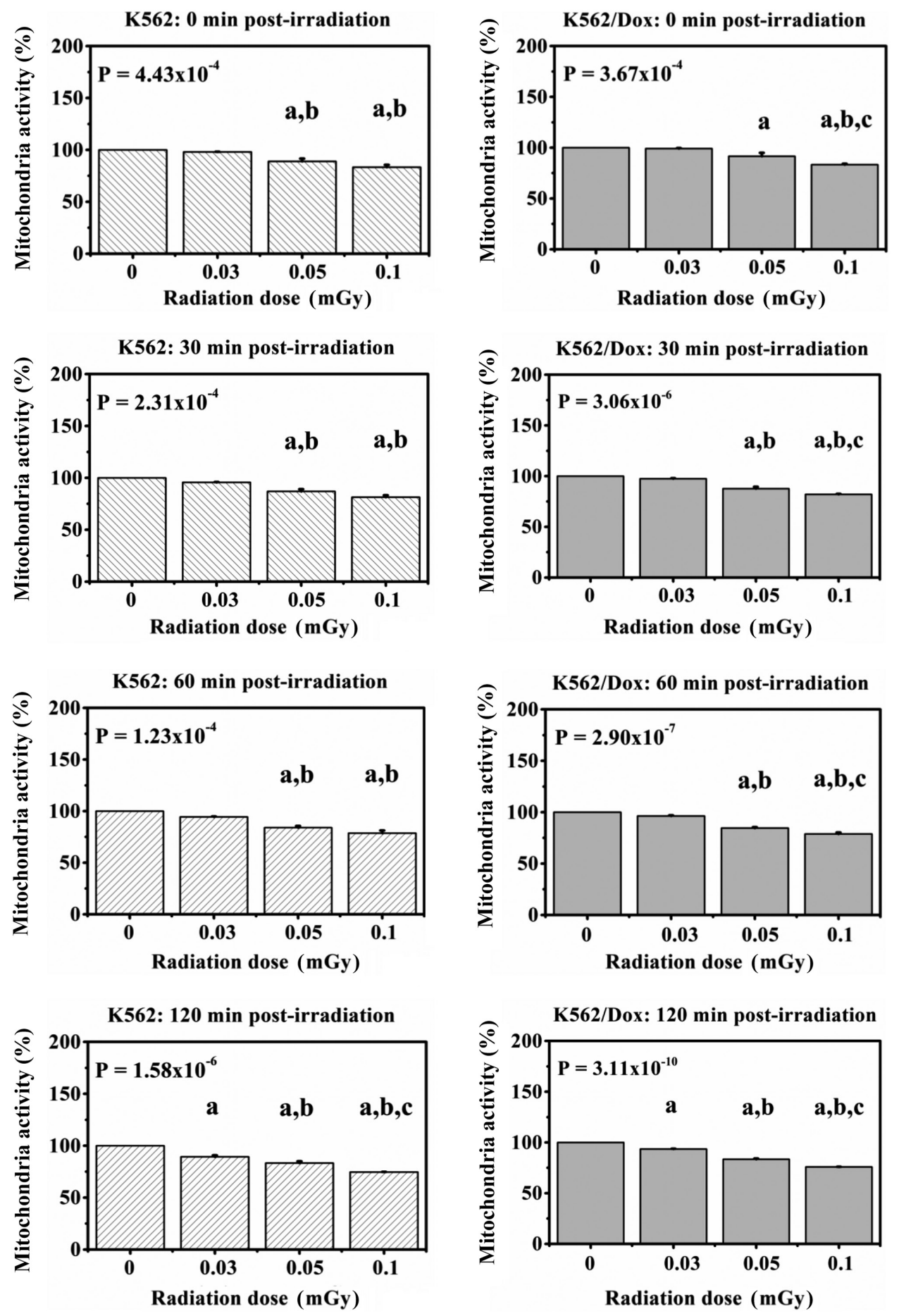

Figure 4. Mitochondrial activity in K562 and K562/Dox cancer cells collected at 0, 30, 60 and 120 min after exposure to various low doses of gamma-rays. ${ }^{\mathrm{a}} \mathrm{P}<0.05$ vs. $0 \mathrm{mGy}$; ${ }^{\mathrm{P}}<0.05$ vs. $0.03 \mathrm{mGy}$; and ${ }^{\mathrm{c}} \mathrm{P}<0.05$ vs. $0.05 \mathrm{mGy}$.

X-rays did not induce a change in mitochondrial membrane potential, number of apoptotic cells and perturbation of the cell cycle in irradiated human lymphocytes compared with non-irradiated lymphocytes. The authors suggested that there were no deleterious effects of low-dose X-rays when blood tissues were exposed in an in vitro system $(30,31,33)$.

The present data demonstrated no changes in ROS levels and percentage of hemolysis of RBCs in irradiated whole blood when compared to the non-irradiated control groups. In addition, the $\mathrm{CBC}$ values in whole blood following in vitro exposure to low-dose gamma-ray groups have not differed compared with the non-irradiated control groups. The current findings suggested that low-dose gamma-ray do not induce any harmful effects to human blood cells. It should be noted that the current results are in agreement with our previous studies $(30,31,33)$ and El-Shanshoury et al (34). These authors showed that statistically significant alteration in white blood cell, red blood cell and platelet count did not occur in rats after exposure to low-dose gamma radiation when compared with non-irradiated groups (34). Conversely, studies have demonstrated radiation-induced red blood cell damage such as increment of hemolysis and lipid peroxidation in RBCs. However, 
those studies on irradiated RBCs involved high dose gamma radiation (27,35-37). It could be suggested that, depending on radiation dose, there are different responses in normal cells (red blood cells) between low- and high-dose radiation.

By contrast, normal cells (red blood cells) with low dose gamma irradiation caused significant increase in ROS levels in both irradiated K562 and K562/Dox cancer cells at all harvest time points, whereas the mitochondrial activity was decreased in both irradiated K562 and K562/Dox cancer cells at all harvest time points relative to non-irradiated cells. ROS and cell type [normal cells (RBCs) vs. cancer cells (K562 and K562/Dox)] were also compared. In the present study, K562 and K562/Dox exhibited sensitivity to low dose gamma radiation more than RBCs. Cancer cells show a wide range of sensitivity to radiation with different radiosensitivities. Low-dose hypersensitivity is found in various cancer cell lines upon receiving radiation (38-41). In addition, Dai et al investigated low dose hyper-radiosensitivity in the cancer cell line A549 irradiated with ${ }^{60} \mathrm{Co}$ gamma-rays at doses of 0-2 Gy. The results showed that A549 cells exhibited low dose hyper-radiosensitivity. The type of death observed in cells was mainly apoptosis (18). Enns et al studied the response of three cancer cell lines, A549, T98G and MCF7, exposed to 0-200 cGy radiation doses from ${ }^{137} \mathrm{Cs}$ source gamma-rays. The authors found that hypersensitivity occurred in the A549 and T98G cancer cells, but not in MCF7 cancer cells at radiation doses $<50 \mathrm{cGy}$. The authors also suggested that hyper-radiosensitivity was involved in p53-dependent apoptosis (19). Short et al (20) investigated low dose hyper-radiosensitivity in the cancer cell lines T98G and U373 irradiated with X-rays. The results showed that hyper-radiosensitivity was observed in both T98G and U373 cancer cells. The authors also demonstrated that low-dose hyper-radiosensitivity depended on the cell cycle phase (20). Therefore, the present results agree with the hypothesis that cancer cell lines exhibit low-dose hypersensitivity to radiation.

ROS have been shown to play important roles in cell proliferation and cell death $(42,43)$. Typically, ROS are produced in cells upon cells that are exposed to radiation in which ROS is mediated from the indirect effects of low linear energy transfer radiation as gamma-rays $(44,45)$. A study has demonstrated that radiation potently induced cancer cell death via generation of ROS and oxidative response in cell organelles such as the mitochondria (46). In addition, Walsh et al performed mitochondrial staining with tetramethyl rhodamine ethyl ester in live MCF-7 and A549 cancer cells after exposure to $55 \mathrm{MeV}$ carbon ions or $3 \mathrm{MeV}$ proton radiation. The results showed that tetramethyl rhodamine ethyl ester levels were decreased in the mitochondria. The authors suggested that there was an induction of mitochondrial membrane depolarization after cancer cells received either protons or carbon ions (47). Leach et al had shown increased DCF fluorescence in A431 cancer cells. It was found that radiation stimulated ROS production in cells after exposure to $3 \mathrm{~Gy}$ of $90 \mathrm{Sr}$ radiation source. The authors also showed transient depolarizing effects of radiation on the mitochondrial membrane potential in A431 cancer cells (48). However, ROS is not only generated in cells by high dose radiation, but also by low-dose radiation, resulting in a number of deleterious effects on cells (21). Hence, the present study hypothesized that low-dose gamma-rays might induce increments of ROS in K562 and K562/Dox cancer cells, resulting in occurrence of oxidative stress that plays a role in decreasing mitochondria activity.

The current study showed the biological responses in K562 and K562/Dox cancer cells to low-dose gamma-rays but did not show that in RBCs. These findings suggested that erythroleukemia was more sensitive to low-dose gamma-rays compared with normal RBCs. In addition, the results of the current study suggested the possibility of using low-dose gamma radiation to treat erythroleukemia.

In conclusion, the current study showed the difference in biological responses in normal cells (RBCs) and cancer cells (K562 and K562/Dox) to low-dose gamma-rays when cells were exposed under in vitro conditions.

\section{Acknowledgements}

Not applicable.

\section{Funding}

This research was partially supported by Chiang Mai University (grant no. R000023314).

\section{Availability of data and materials}

All data generated or analyzed during this study are included in this published article.

\section{Authors' contributions}

BS, PH, NK and NS performed the experiments. ST, SK and CU interpreted the data and revised the manuscript. MT conceived and designed the current study, performed the experiments, analyzed and interpreted the data, and drafted and revised the manuscript. All authors have read and approved the final manuscript.

\section{Ethics approval and consent to participate}

Blood sample collections were performed under the approved guidelines by the Institutional Committees on Research Involving Human Subjects and approval of the Faculty of Associated Medical Sciences, Chiang Mai University (approval no. AMSEC-62EM-002).

\section{Patient consent for publication}

Not applicable.

\section{Competing interests}

The authors declare that they have no competing interests.

\section{References}

1. Rithidech KN, Golightly M and Whorton E: Analysis of cell cycle in mouse bone marrow cells following acute in vivo exposure to 56Fe ions. J Radiat Res 49: 437-443, 2008.

2. Jelveh S, Kaspler P, Bhogal N, Mahmood J, Lindsay PE, Okunieff P, Doctrow SR, Bristow RG and Hill RP: Investigations of antioxidant-mediated protection and mitigation of radiation-induced DNA damage and lipid peroxidation in murine skin. Int J Radiat Biol 89: 618-627, 2013. 
3. 3.Villani P, Fresegna AM, Ranaldi R, Eleuteri P, Paris L, Pacchierotti $F$ and Cordelli E: X-ray induced DNA damage and repair in germ cells of PARP1(-/-) male mice. Int J Mol Sci 14: 18078-18092, 2013.

4. Tungjai M, Whorton EB and Rithidech KN: Persistence of apoptosis and inflammatory responses in the heart and bone marrow of mice following whole-body exposure to ${ }^{28} \mathrm{Silicon}\left({ }^{28} \mathrm{Si}\right)$ ions. Radiat Environ Biophys 52: 339-350, 2013.

5. Olivieri G, Bodycote J and Wolff S: Adaptive response of human lymphocytes to low concentrations of radioactive thymidine. Science 223: 594-597, 1984.

6. Bond VP, Benary V and Sondhaus CA: A different perception of the linear, nonthreshold hypothesis for low-dose irradiation. Proc Natl Acad Sci USA 88: 8666-8670, 1991

7. Azzam EI, de Toledo SM, Raaphorst GP and Mitchel RE: Low-dose ionizing radiation decreases the frequency of neoplastic transformation to a level below the spontaneous rate in C3H 10T1/2 cells. Radiat Res 146: 369-373, 1996.

8. Wolff S: The adaptive response in radiobiology: Evolving insights and implications. Environ Health Perspect 106 (Suppl 1): 277-283, 1998.

9. Redpath JL, Liang D, Taylor TH, Christie C and Elmore E: The shape of the dose-response curve for radiation-induced neoplastic transformation in vitro: Evidence for an adaptive response agains neoplastic transformation at low doses of low-LET radiation. Radiat Res 156: 700-707, 2001

10. Feinendegen LE: Evidence for beneficial low level radiation effects and radiation hormesis. Br J Radiol 78: 3-7, 2005.

11. Scott BR and Di Palma J: Sparsely ionizing diagnostic and natural background radiations are likely preventing cancer and other genomic-instability-associated diseases. Dose Response 5 : 230-255, 2006

12. Elmore E, Lao XY, Kapadia R, Giedzinski E, Limoli C and Redpath JL: Low doses of very low-dose-rate low-LET radiation suppress radiation-induced neoplastic transformation in vitro and induce an adaptive response. Radiat Res 169: 311-318, 2008

13. Rithidech KN and Scott BR: Evidence for radiation hormesis after in vitro exposure of human lymphocytes to low doses of ionizing radiation. Dose Response 6: 252-271, 2008.

14. Mitchel RE: The dose window for radiation-induced protective adaptive responses. Dose Response 8: 192-208, 2009.

15. Rithidech KN, Udomtanakunchai C, Honikel L and Whorton E: Lack of genomic instability in bone marrow cells of SCID mice exposed whole-body to low-dose radiation. Int J Environ Res Public Health 10: 1356-1377, 2013.

16. Rithidech KN, Udomtanakunchai C, Honikel LM and Whorton EB: No evidence for the in vivo induction of genomic instability by low doses of CS gamma-rays in bone marrow cells of BALB/CJ and C57BL/6J mice. Dose Response 10: 11-36, 2012

17. Yu HS, Liu ZM, Yu XY, Song AQ, Liu N and Wang H: Low-dose radiation induces antitumor effects and erythrocyte system hormesis. Asian Pac J Cancer Prev 14: 4121-4126, 2013.

18. Dai X, Tao D, Wu H and Cheng J: Low dose hyper-radiosensitivity in human lung cancer cell line A549 and its possible mechanisms. J Huazhong Univ Sci Technolog Med Sci 29: 101-106, 2009.

19. Enns L, Bogen KT, Wizniak J, Murtha AD and Weinfeld M: Low-dose radiation hypersensitivity is associated with p53-dependent apoptosis. Mol Cancer Res 2: 557-566, 2004.

20. Short SC, Woodcock M, Marples B and Joiner MC: Effects of cell cycle phase on low-dose hyper-radiosensitivity. Int J Radiat Biol 79: 99-105, 2003.

21. Smith JT, Willey NJ and Hancock JT: Low dose ionizing radiation produces too few reactive oxygen species to directly affect antioxidant concentrations in cells. Biol Lett 8: 594-597, 2012.

22. Rithidech KN, Tungjai M and Whorton EB: Protective effect of apigenin on radiation-induced chromosomal damage in human lymphocytes. Mutat Res 585: 96-104, 2005.

23. Betteridge DJ: What is oxidative stress? Metabolism 49 (Suppl 1): 3-8, 2000.

24. Feinendegen LE, Pollycove M and Sondhaus CA: Responses to low doses of ionizing radiation in biological systems. Nonlinearity Biol Toxicol Med 2: 143-171, 2004

25. Spitz DR, Azzam EI, Li JJ and Gius D: Metabolic oxidation/ reduction reactions and cellular responses to ionizing radiation: A unifying concept in stress response biology. Cancer Metastasis Rev 23: 311-322, 2004.

26. Zbikowska HM, Antosik A, Szejk M, Bijak M and Nowak P: A moderate protective effect of quercetin against $\gamma$-irradiation- and storage-induced oxidative damage in red blood cells for transfusion. Int J Radiat Biol 90: 1201-1210, 2014.
27. Zbikowska HM and Antosik A: Irradiation dose-dependent oxidative changes in red blood cells for transfusion. Int J Radiat Biol 88: 654-660, 2012.

28. Diederich L, Suvorava T, Sansone R, Keller TC IV, Barbarino F, Sutton TR, Kramer CM, Lückstädt W, Isakson BE, Gohlke H, et al: On the Effects of Reactive Oxygen Species and Nitric Oxide on Red Blood Cell Deformability. Front Physiol 9: 332, 2018.

29. Baroni F, Marraccini C, Merolle L, Piccagli V, Lambertini D, Iori M, Fasano T, Casali E, Spisni A, Baricchi R, et al: Red blood cells metabolome changes upon treatment with different X-ray irradiation doses. Ann Hematol 97: 1909-1917, 2018.

30. Tungjai M, Phathakanon N, Ketnuam P, Tinlapat J and Kothan S: Determination of hemolysis, osmotic fragility and fluorescence anisotropy on irradiated red blood cells as a function of $\mathrm{kV}$ of medical diagnostic X-rays. J Radiat Res 16: 123-127, 2018.

31. Tungjai M, Sopapang J, Tasri N, Osothsongkroh C, Jantarato A and Kothan S: The effects of medical diagnostic low dose X-rays after in vitro exposure of human red blood cells: Hemolysis and osmotic fragility. Toxicol Environ Health Sci 11: 237-243, 2019.

32. International Atomic Energy Agency: Effects of ionizing radiation on blood and blood components: A survey. IAEA-TECDOC-934, Vienna, 1997.

33. Tungjai M, Phathakanon $\mathrm{N}$ and Rithidech KN: Effects of medical diagnostic low-dose $\mathrm{X}$ rays on human lymphocytes: mitochondrial membrane potential, apoptosis and cell cycle. Health Phys 112: 458-464, 2017.

34. El-Shanshoury H, El-Shanshoury G and Abaza A: Evaluation of low dose ionizing radiation effect on some blood components in animal model. J Radiat Res Appl Sci 9: 282-293, 2016.

35. Antosik A, Czubak K, Gajek A, Marczak A, Glowacki R, Borowczyk $\mathrm{K}$ and Zbikowska HM: Influence of pre-storage irradiation on the oxidative stress markers, membrane integrity, size and shape of the cold stored red blood cells. Transfus Med Hemother 42: 140-148, 2015.

36. Dumaswala UJ, Zhuo L, Jacobsen DW, Jain SK and Sukalski KA: Protein and lipid oxidation of banked human erythrocytes: Role of glutathione. Free Radic Biol Med 27: 1041-1049, 1999.

37. Anand AJ, Dzik WH, Imam A and Sadrzadeh SM: Radiation-induced red cell damage: Role of reactive oxygen species. Transfusion 37: 160-165, 1997.

38. Joiner MC, Marples B, Lambin P, Short SC and Turesson I: Low-dose hypersensitivity: Current status and possible mechanisms. Int J Radiat Oncol Biol Phys 49: 379-389, 2001.

39. Wouters BG and Skarsgard LD: The response of a human tumor cell line to low radiation doses: Evidence of enhanced sensitivity. Radiat Res 138 (Suppl 1): S76-S80, 1994.

40. Skarsgard LD, Skwarchuk MW, Wouters BG and Durand RE Substructure in the radiation survival response at low dose in cells of human tumor cell lines. Radiat Res 146: 388-398, 1996.

41. Wouters BG, Sy AM and Skarsgard LD: Low-dose hypersensitivity and increased radioresistance in a panel of human tumor cell lines with different radiosensitivity. Radiat Res 146: 399-413, 1996.

42. Liou GY and Storz P: Reactive oxygen species in cancer. Free Radic Res 44: 479-496, 2010.

43. Kim W, Lee S, Seo D, Kim D, Kim K, Kim E, Kang J, Seong KM, Youn $\mathrm{H}$ and Youn B: Cellular Stress Responses in Radiotherapy. Cells 8: 8, 2019.

44. Kawamura K, Qi F and Kobayashi J: Potential relationship between the biological effects of low-dose irradiation and mitochondrial ROS production. J Radiat Res 59 (Suppl 2): ii91-ii97, 2018.

45. Azzam EI, Jay-Gerin JP and Pain D: Ionizing radiation-induced metabolic oxidative stress and prolonged cell injury. Cancer Lett 327: 48-60, 2012.

46. Wang JS, Wang HJ and Qian HL: Biological effects of radiation on cancer cells. Mil Med Res 5: 20, 2018.

47. Walsh DW, Siebenwirth C, Greubel C, Ilicic K, Reindl J, Girst S, Muggiolu G, Simon M, Barberet P, Seznec H, et al: Live cell imaging of mitochondria following targeted irradiation in situ reveals rapid and highly localized loss of membrane potential. Sci Rep 7: 46684, 2017.

48. LeachJK,VanTuyleG,LinPS,Schmidt-UllrichRandMikkelsenRB: Ionizing radiation-induced, mitochondria-dependent generation of reactive oxygen/nitrogen. Cancer Res 61: 3894-3901, 2001. 